NASA Technical Memorandum 113159

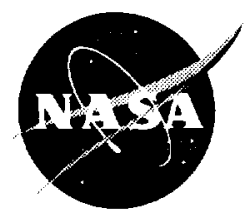

\title{
SiC-Based Schottky Diode Gas Sensors
}

Gary W. Hunter, Philip G. Neudeck, and Liang-Yu Chen

Lewis Research Center, Cleveland, Ohio

Dak Knight

Cortez III Service Corporation, Cleveland, Ohio

Chung-Chiun Liu and Quing-Hai Wu

Case Western Reserve University, Cleveland, Ohio

Prepared for the

International Conference on SiC and Related Materials

sponsored by Linkoping University

Stockholm, Sweden, August 31-September 5, 1997

National Aeronautics and

Space Administration

Lewis Research Center 
Available from

NASA Center for Aerospace Information 800 Elkridge Landing Road

Lynthicum, MD 21090-2934

Price Code: A02
National Technical Information Service 5287 Port Royal Road Springfield, VA 22100 Price Code: A02 


\title{
SiC-BASED SCHOTTKY DIODE GAS SENSORS
}

\author{
Gary W. Hunter ${ }^{1}$, Philip G. Neudeck ${ }^{1}$, Liang-Yu Chen ${ }^{1}$, Dak Knight ${ }^{2}$, \\ Chung-Chiun $\mathrm{Liu}^{3}$ and Quing-Hai $\mathrm{Wu}^{3}$ \\ ${ }^{1}$ NASA Lewis Research Center and \\ ${ }^{2}$ Cortez III Service Corporation/NASA Lewis Research Center \\ Cleveland, Ohio 44135 USA \\ ${ }^{3}$ Electronics Design Center, \\ Case Western Reserve University \\ Cleveland, Ohio 44106 USA
}

Keywords: SiC, gas, emission, sensor, high temperature

\begin{abstract}
Silicon carbide based Schottky diode gas sensors are being developed for high temperature applications such as emission measurements. Two different types of gas sensitive diodes will be discussed in this paper. By varying the structure of the diode, one can affect the diode stability as well as the diode sensitivity to various gases. It is concluded that the ability of SiC to operate as a high temperature semiconductor significantly enhances the versatility of the Schottky diode gas sensing structure and will potentially allow the fabrication of a SiC-based gas sensor array for versatile high temperature gas sensing applications.
\end{abstract}

\subsection{Introduction}

The sensitive detection of hydrogen $\left(\mathrm{H}_{2}\right)$, hydrocarbons $\left(\mathrm{C}_{\mathrm{x}} \mathrm{H}_{\mathrm{y}}\right)$, and nitrogen oxides $\left(\mathrm{NO}_{\mathrm{x}}\right)$ is important for emission monitoring, chemical process control, and other high temperature applications. The development of $\mathrm{SiC}$ as a high temperature semiconductor allows the fabrication of sensors which function in conditions where silicon $(\mathrm{Si})$ based technology is inoperable. This allows the development of gas sensitive electronic structures such as Schottky diodes which can operate at temperatures high enough to allow the detection of $\mathrm{C}_{\mathrm{x}} \mathrm{H}_{\mathrm{y}}$ or $\mathrm{NO}_{\mathrm{x}}$. The advantage of a Schottky diode structure in gas sensing applications is its high sensitivity. This is especially useful in applications such as emission monitoring where the gas concentrations to be measured are low.

Linkoping University has investigated a gas sensitive Schottky diode structure composed of $\mathrm{Pt}$ on $15 \mathrm{~nm}$ of $\mathrm{TaSi}_{\mathrm{x}}$ on a native oxide of $\mathrm{SiO}_{2}$ on $\mathrm{SiC}$. This sensor has a very quick response time to $\mathrm{C}_{\mathrm{x}} \mathrm{H}_{\mathrm{y}}$ and is stable for extended periods at high temperatures. The magnitude of the diode signal changes by less than an order of magnitude as the ambient is changed from $2 \%$ oxygen in argon to $1 \%$ propane in argon at $550^{\circ} \mathrm{C}[1-2]$.

A simple and highly sensitive Schottky diode structure is a catalytic metal directly deposited on a $\mathrm{SiC}$ semiconductor (MS). Previously, we have investigated $\mathrm{Pd}$ directly deposited on $\mathrm{SiC}(\mathrm{Pd} / \mathrm{SiC})$ [3]. This Schottky diode is very sensitive to $\mathrm{H}_{2}$ and $\mathrm{C}_{\mathrm{x}} \mathrm{H}_{\mathrm{y}}$ : changes of more than a factor of a 1000 in the forward current have been observed at $300^{\circ} \mathrm{C}$ in response to $360 \mathrm{ppm}$ of $\mathrm{H}_{2}$, propylene, and ethylene. However, the $\mathrm{Pd} / \mathrm{SiC}$ diode response drifts if operated at high temperatures for extended periods of time due to, in part, reactions between the Pd and SiC.

A major thrust of the development effort at NASA Lewis Research Center (LeRC) and Case Western Reserve University (CWRU) is the stabilization of the SiC-based sensor structure for longterm, high temperature operation while maintaining high sensitivity [3-4]. Of equal importance is 
the ability to selectively differentiate between various gases in a mixture. This can be accomplished by using an array of high temperature gas sensors [5] composed of both $\mathrm{SiC}$-based sensors and other sensing materials and platforms. The end result would be, in effect, a high temperature electronic nose for harsh environments. The realization of this objective entails the fabrication of a variety of SiC-based gas sensors with varying sensitivities to different gases.

The purpose of this paper is to discuss the SiC-based gas sensing Schottky diode structures under development at NASA LeRC and CWRU. Two types of structures will be discussed: 1) A catalytic alloy, palladium chrome $(\mathrm{PdCr})$, deposited directly on the $\mathrm{SiC}$ forming a MS structure and 2) A catalytic metal (Pd) deposited on a chemically reactive insulator tin oxide $\left(\mathrm{SnO}_{2}\right)$ adherent on the $\mathrm{SiC}$ forming a metal-reactive insulator-semiconductor structure (MRIS). It is concluded that both structures show improved stability over the $\mathrm{Pd} / \mathrm{SiC}$ diode while maintaining high sensitivity.

\subsection{Device Fabrication and Testing}

The characterization of two types of samples will be discussed in this paper. The first type is a $\mathrm{PdCr} / \mathrm{SiC}$ Schottky diode while the second is a sample containing both $\mathrm{Pd} / \mathrm{SiC}$ and $\mathrm{Pd} / \mathrm{SnO} 2 / \mathrm{SiC}$ Schottky diodes on the same chip. In both samples, a 4-5 $\mu \mathrm{m}$ thick alpha-SiC epilayer was grown by chemical vapor deposition on a commercially available alpha-SiC substrate. A backside contact was achieved by sputtering aluminum onto the bottom of the wafer.

The $\mathrm{PdCr} / \mathrm{SiC}$ diodes were formed by co-sputtering with a Pd target and a separate $\mathrm{Cr}$ target approximately 400 angstroms $(\AA)$ of $\mathrm{PdCr}$ metal onto the as-grown SiC epilayer surface and patterning by a lift-off technique to form circular PdCr Schottky patterns of diameter $200 \mu \mathrm{m}$. The $\mathrm{Pd} / \mathrm{SiC}$ and $\mathrm{Pd} / \mathrm{SnO}_{2} / \mathrm{SiC}$ Schottky diodes were formed in the following manner: a thin layer (approx. $50 \AA$ ) of $\mathrm{SnO}_{2}$ was sputter deposited onto half of the substrate while the other half of the substrate was masked during this deposition and was left as-grown. Circular Pd contacts were formed by sputter deposition and lift-off as done with the $\mathrm{PdCr} / \mathrm{SiC}$ diodes. Thus, one side of the sample formed $\mathrm{Pd} / \mathrm{SnO}_{2} / \mathrm{SiC}$ Schottky diodes while the other side of the sample formed $\mathrm{Pd} / \mathrm{SiC}$ Schottky diodes; in effect, this is a small sensor "array" composed of two types of diode elements.

The gas sensor testing facility and sample connections have been described elsewhere [3]. The sample rested on the hot stage whose temperature was controlled from room temperature to $425^{\circ} \mathrm{C}$. Current-time (I-t) measurements were taken to characterize the diode response as a function of time during exposure to a variety of gases, and current-voltage (I-V) measurements were taken to characterize the diodes electronics properties in given environment. The forward voltage at which the current was measured was chosen to maximize the diode response to the hydrogen-bearing gas and to minimize series resistance effects.

\subsection{Results and Discussion}

\subsection{PdCr MS Schottky Diode}

The advantages of $\mathrm{PdCr}$ as a high temperature alloy have been explored extensively in strain gage applications [6]. It is a stable high temperature material which is able to provide static strain measurements at temperature up to $1100^{\circ} \mathrm{C}$. However, its use in a gas-sensing SiC-based structure depends on not only its inherent stability but also such factors as the alloy's reactivity to $\mathrm{SiC}$ and the catalytic interactions of $\mathrm{PdCr}$ alloy with the gases to be measured. The sensitivity and stability of the $\mathrm{PdCr} / \mathrm{SiC}$ diode were characterized in the following manner.

An as-deposited diode was first operated at $100^{\circ} \mathrm{C}$ to establish the baseline electronic properties. Current-time measurements at $0.7 \mathrm{~V}$ were taken as the sensor was exposed to 20 minutes of air, 20 minutes in nitrogen $\left(\mathrm{N}_{2}\right), 20$ minutes of $120 \mathrm{ppm} \mathrm{H}_{2}$ in $\mathrm{N}_{2}\left(\mathrm{~N}_{2} / \mathrm{H}_{2} \mathrm{mix}\right), 10$ minutes of $\mathrm{N}_{2}$, and then 
10 minutes of air. After the baseline condition was established, the diode was heat treated at $425^{\circ} \mathrm{C}$ in air for periods of at least 13 hours. The diode temperature was then decreased to $100^{\circ} \mathrm{C}$ and the diode was then characterized in the same manner used to establish the baseline. This cycle of heating followed by diode characterization at $100^{\circ} \mathrm{C}$ was repeated until the total time of heating at $425^{\circ} \mathrm{C}$ was 250 hours.

Figures 1-2 demonstrate that $\mathrm{PdCr} / \mathrm{SiC}$ is a viable diode structure for high temperature gas sensing applications with improved stability compared to $\mathrm{Pd} / \mathrm{SiC}$ [3]. Fig. 1 shows the current at 0.7 $\mathrm{V}$ at $100^{\circ} \mathrm{C}$ in air and in the $\mathrm{N}_{2} / \mathrm{H}_{2}$ mix as a function of heating time. While the air baseline current drifts lower with heating time, the current in the $\mathrm{N}_{2} / \mathrm{H}_{2}$ mix is relatively stable after the initial heating period of 40 hours. This is demonstrated in Fig. 2 where $\mathrm{I}-\mathrm{t}$ is shown for various gas mixtures: the sensor baseline in air is much lower after 250 hours of heating than at 40 hours, but the sensor current in the $\mathrm{N}_{2} / \mathrm{H}_{2}$ mix is the same within a factor of 3 . Thus, the diode's sensitivity to $\mathrm{H}_{2}$ is nearly two orders of magnitude larger at this voltage after 250 hours of heating with the corresponding magnitude of the signal in $\mathrm{H}_{2}$ being nearly constant after 40 hours.

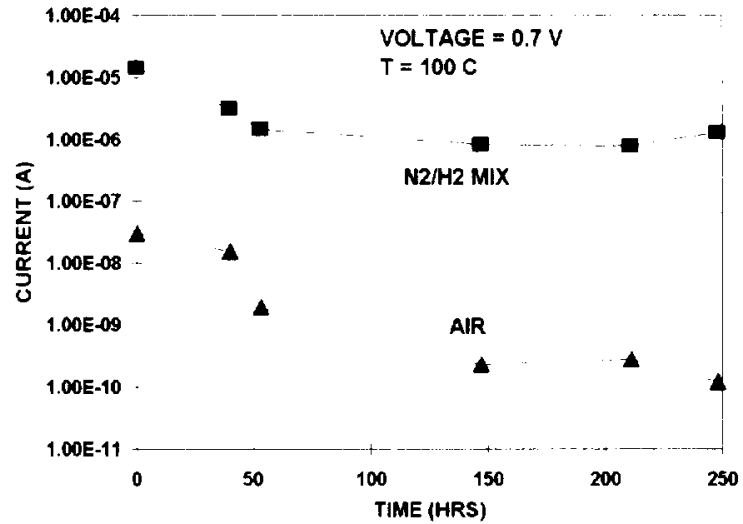

Fig. 1. The forward current at $100^{\circ} \mathrm{C}$ vs heating time at $425^{\circ} \mathrm{C}$ in air (A) and in $120 \mathrm{ppm} \mathrm{H}_{2}$ in $\mathrm{N}_{2}(\mathbf{\square})$.

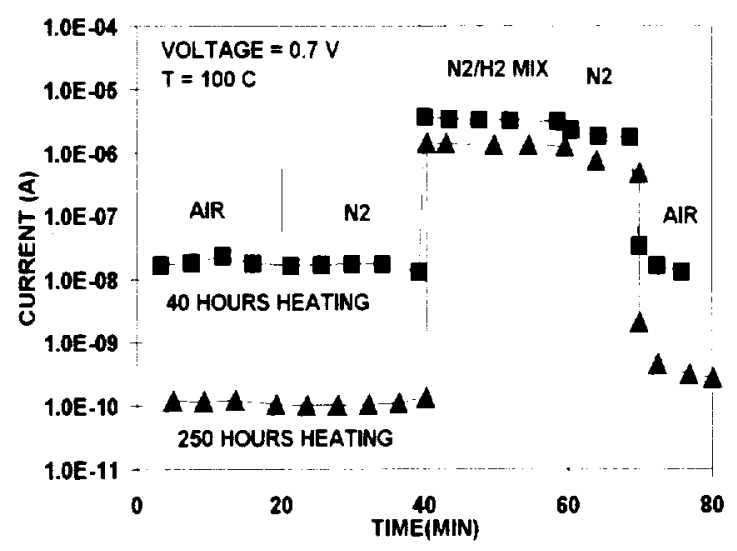

Fig. 2. The forward current vs time at $100^{\circ} \mathrm{C}$ after 40 hours ( $\square$ ) and 250 hours (4) heating at $425^{\circ} \mathrm{C}$ in air.

\subsection{Metal-Reactive Insulator SiC Schottky Diodes}

A wide variety of materials, e.g. metal oxides such as $\mathrm{SnO}_{2}$, are sensitive to $\mathrm{C}_{\mathrm{x}} \mathrm{H}_{\mathrm{y}}$ and $\mathrm{NO}_{\mathrm{x}}$ at high temperatures. These materials could be incorporated as a sensitive component into MIS structures and, unlike silicon, SiC-based devices can be operated at high enough temperatures for these materials to be reactive to gases such as $\mathrm{C}_{\mathrm{x}} \mathrm{H}_{\mathrm{y}}$ and $\mathrm{NO}_{\mathrm{x}}$ [3]. This results in a new type of gas sensitive structure: a metal-reactive insulator-semiconductor structure (MRIS). The advantages of this type of SiC-based structure include 1) increased sensor sensitivity since the diode responds to gas reactions with not only the catalytic metal but with the reactive insulator as well. 2) improved sensor stability since the gas reactive insulator can act as a barrier layer between the metal and $\mathrm{SiC}$ potentially stabilizing the sensor's structure. 3) the ability to vary sensor selectivity by varying the reactive insulator element. This paper demonstrates the use of this type of MRIS sensor. 
Operation of a $\mathrm{Pd} / \mathrm{SnO}_{2} / \mathrm{SiC}$ sensor and comparison of this sensor with a $\mathrm{Pd} / \mathrm{SiC}$ sensor on the same chip is shown in Figures 3-4. Two different carrier gases are used: pure $\mathrm{N}_{2}$ and an air $/ \mathrm{N}_{2}$ mixture. The sensors are first exposed to air for 15 minutes, then the carrier gas for 15 minutes, followed by $400 \mathrm{ppm}$ of a hydrogen-bearing gas in the carrier gas, 5 minutes of the carrier gas, and finally 10 minutes in air. The air $\mathrm{N}_{2}$ carrier gas had a constant oxygen concentration of $10 \%$.

The effect of the thin $\mathrm{SnO}_{2}$ layer is most easily seen in the I-V curves of Fig. 3 for the $\mathrm{Pd} / \mathrm{SnO}_{2} / \mathrm{SiC}$ and $\mathrm{Pd} / \mathrm{SiC}$ diodes respectively. The $\mathrm{I}-\mathrm{V}$ curve for the $\mathrm{Pd} / \mathrm{SnO}_{2} / \mathrm{SiC}$ diode in Fig. 3 shows parallel shunt resistance for voltages below $1.0 \mathrm{~V}$, and exponential Schottky behavior above $1.0 \mathrm{~V}$ until series resistance effects begin to dominate. The barrier height derived from the exponential portion of the curves suggests that the $\mathrm{SnO}_{2}$ increases the barrier height of the diode. The effect of the $400 \mathrm{ppm} \mathrm{H}_{2}$ in $\mathrm{N}_{2}$ on the I-V curve was to increase the current for a given voltage, with the increase in current in the shunt resistance region being somewhat lower than the increase in the Schottky region. This increase in current (resistance decrease) was also noted when the resistance across just the $\mathrm{SnO}_{2}$ was monitored with probes under the same conditions. Thus, $\mathrm{SnO}_{2}$ affects the response to hydrogen of the diode with higher sensitivity to hydrogen noted in the exponential Schottky-like conduction region. In contrast, the $\mathrm{Pd} / \mathrm{SiC}$ diode shows two types of I-V behavior: an exponential response in the low voltage regions and a series resistance effects at higher voltages. These results clearly show that the $\mathrm{SnO}_{2}$ changes the sensor's basic electronic behavior and the sensor response to $\mathrm{H}_{2}$.

Fig. 4 shows the response of both the $\mathrm{Pd} / \mathrm{SiC}$ and the $\mathrm{Pd} / \mathrm{SnO}_{2} / \mathrm{SiC}$ diodes to $\mathrm{H}_{2}$, methane, and propylene that were aged over a several week period at $350^{\circ} \mathrm{C}$. The $\mathrm{Pd} / \mathrm{SiC}$ sensor does not respond to $400 \mathrm{ppm}$ of $\mathrm{H}_{2}$ (Fig. 4) or propylene and methane (not shown) in the air $/ \mathrm{N}_{2}$ mixture. However, the $\mathrm{Pd} / \mathrm{SnO}_{2} / \mathrm{SiC}$ sensor responds with increasing signal strength to methane, $\mathrm{H}_{2}$, and propylene. That the $\mathrm{Pd} / \mathrm{SnO}_{2} / \mathrm{SiC}$ sensor response to propylene is stronger than that to $\mathrm{H}_{2}$ is significant; the $\mathrm{Pd} / \mathrm{SiC}$ response in $\mathrm{N}_{2}$ [3] and in $\mathrm{N}_{2}$ /air to propylene and $\mathrm{H}_{2}$ was reversed. Thus, the addition of the $\mathrm{SnO}_{2}$ layer makes possible the detection of gases not detected without the layer. It should be noted that the response of the $\mathrm{Pd} / \mathrm{SiC}$ sensor degraded over the several week period of $350^{\circ} \mathrm{C}$ operation while the $\mathrm{Pd} / \mathrm{SnO}_{2} / \mathrm{SiC}$ sensor remained relatively stable.

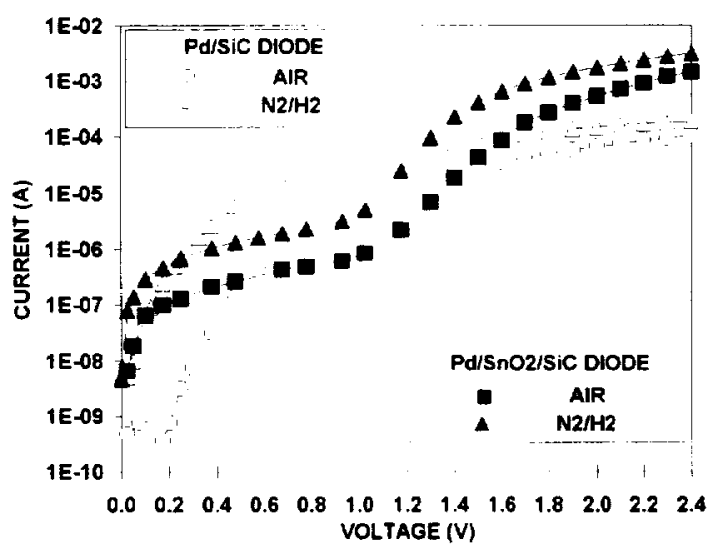

Fig. 3. Current vs voltage at $350^{\circ} \mathrm{C}$ for a $\mathrm{Pd} / \mathrm{SiC}$ diode in air (O) and the $400 \mathrm{ppm} \mathrm{N}_{2} / \mathrm{H}_{2}$ mix $(\Delta)$, and a $\mathrm{Pd} / \mathrm{SnO}_{2} / \mathrm{SiC}$ diode in air (a) and the $\mathrm{N}_{2} / \mathrm{H}_{2} \operatorname{mix}(\boldsymbol{\Lambda})$.

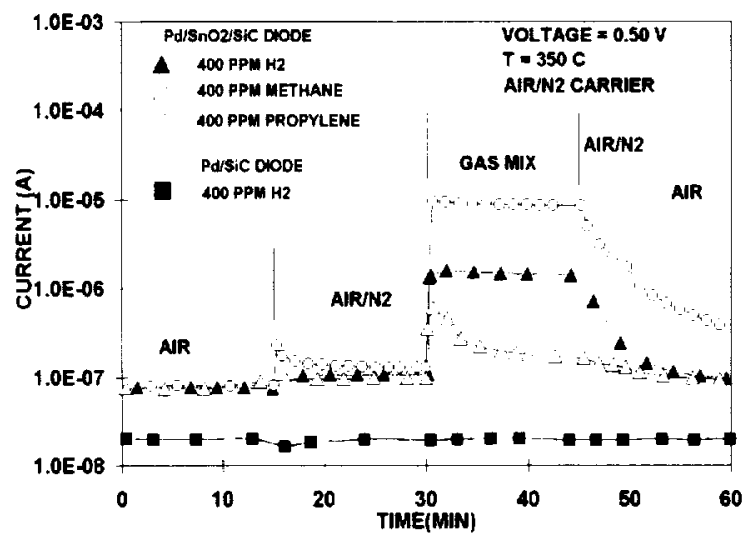

Fig. 4. Current vs time at $350^{\circ} \mathrm{C}$ for a $\mathrm{Pd} / \mathrm{SiC}$ diode exposed to $400 \mathrm{ppm} \mathrm{H}_{2}(\square)$ and a $\mathrm{Pd} / \mathrm{SnO}_{2} / \mathrm{SiC}$ diode exposed to $400 \mathrm{ppm}$ of $\mathrm{H}_{2}$ $(\Delta)$, methane $(\Delta)$, and propylene $(0)$. 


\subsection{Conclusions and Future Plans}

The demonstration of both the $\mathrm{PdCr} / \mathrm{SiC}$ MS diode and the $\mathrm{Pd} / \mathrm{SnO}_{2} / \mathrm{SiC}$ MRIS diode as stable and sensitive gas sensors shows the versatility of $\mathrm{SiC}$ as semiconductor for high temperature gas sensing applications. Future plans include the investigation of other MS and MRIS structures with the eventual goal of forming SiC-based arrays for high temperature gas detection.

\subsection{Acknowledgments}

The authors would like to acknowledge the contributions of Dr. W. D. Williams, Dr. J. F. Lei, Dr. L. Matus, G. Bansal, and Dr. D. Larkin of NASA LeRC, and Jeremy Petit of NYMANASA LeRC. L. Chen is a NRC fellow. Send correspondences to Gary Hunter, E-mail: ghunter@lerc.nasa.gov

\subsection{References}

[1] M. Karlsteen, A. Baranzahi, A. L. Spetz, M. Willander, and I. Lundstrom, J. Electron. Mat. 26 (1995) p. 853.

[2] P. Tobias, A. Baranzahi, A. L. Spetz, O. Kordina, E. Janzen, and I. Lundstrom, IEEE Elec, Dev. Lett. 18 (1997), p. 287.

[3] L.-Y. Chen, G. W. Hunter, P. G. Neudeck, D. Knight; C. C. Liu, and Q. H. Wu, "SiC-Based Gas Sensors", proceedings of the $190^{\text {th }}$ Meeting of the Electrochemical Society, San Antonio, TX., 1996 and references therein.

[4] L.-Y. Chen, G. W. Hunter, P. G. Neudeck, D. Knight, J. Petit and G. Bansal, J. Vac. Sci. Tech A, 15, (1997) p. 1228.

[5] G. W. Hunter, L.-Y. Chen, P. G. Neudeck, D. Knight, C. C. Liu, Q. H. Wu and H. J. Zhou, "Development of High Temperature Gas Sensor Technology", presented at 42nd Turbo Expo' 97, NASA Technical Memorandum 107442, (1997).

[6] Lei, J. F., Plat. Met. Rev., 35 (1991) p. 65. 


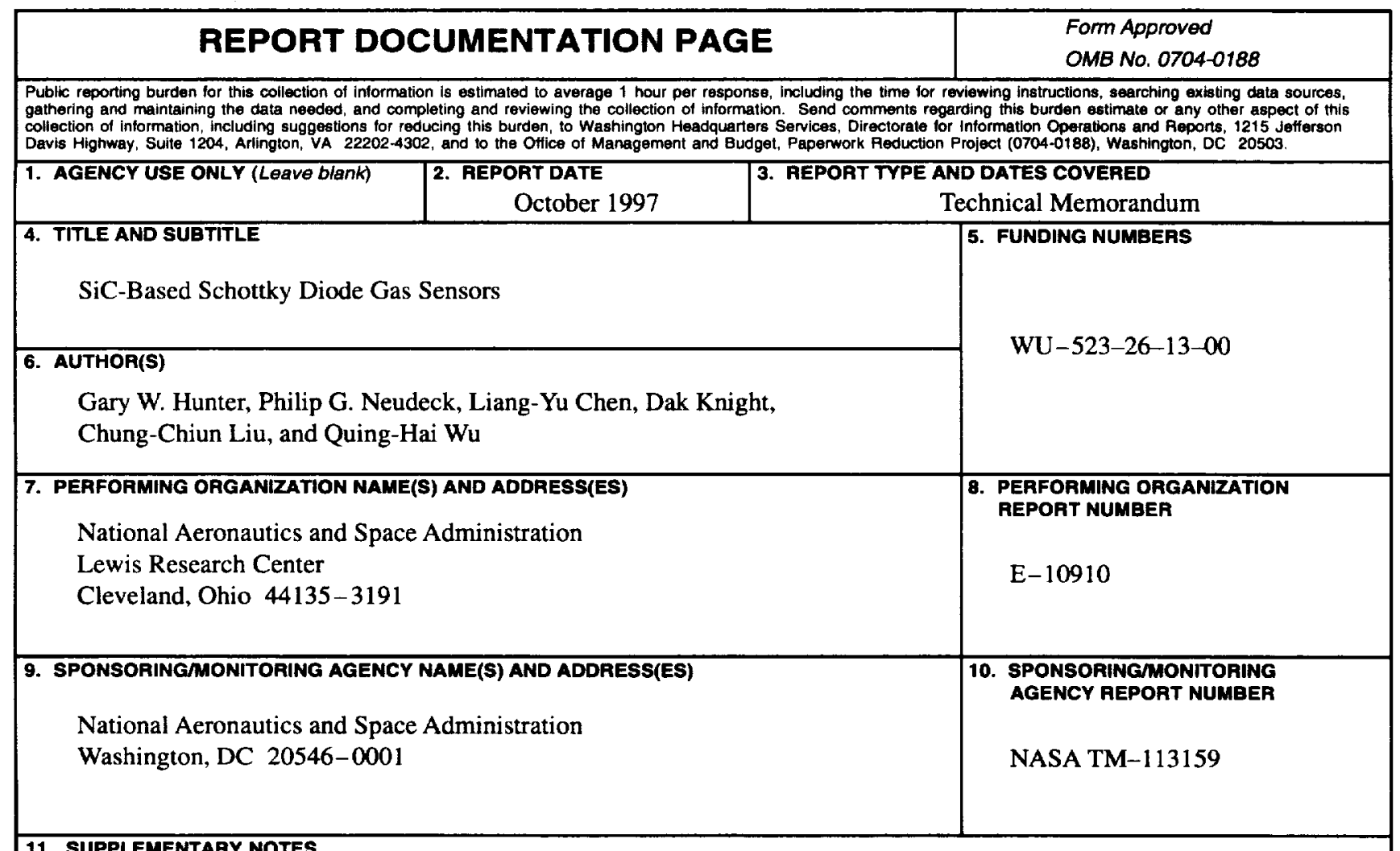

\section{SUPPLEMENTARY NOTES}

Prepared for the International Conference on SiC and Related Materials sponsored by Linkoping University, Stockholm, Sweden, August 31-September 5, 1997. Gary W. Hunter, Philip G. Neudeck, Liang-Yu Chen, NASA Lewis Research Center; Dak Knight, Cortez III Service Corporation, 21000 Brookpark Rd., Cleveland, Ohio 44135; Chung-Chiun Liu, and Quing-Hai Wu, Case Western Reserve University, Electronics Design Center, Cleveland, Ohio 44106. Responsible person, Gary W. Hunter, organization code 5510, (216) 433-6459.

\begin{tabular}{|l|l}
\hline 12a. DISTRIBUTIONAVAILABILITY STATEMENT & 12b. DISTRIBUTION CODE
\end{tabular}

Unclassified - Unlimited

Subject Category: 35 Distribution: Nonstandard

This publication is available from the NASA Center for AeroSpace Information, (301) 621-0390.

13. ABSTAACT (Maximum 200 words)

Silicon carbide based Schottky diode gas sensors are being developed for high temperature applications such as emission measurements. Two different types of gas sensitive diodes will be discussed in this paper. By varying the structure of the diode, one can affect the diode stability as well as the diode sensitivity to various gases. It is concluded that the ability of $\mathrm{SiC}$ to operate as a high temperature semiconductor significantly enhances the versatility of the Schottky diode gas sensing structure and will potentially allow the fabrication of a SiC-based gas sensor arrays for versatile high temperature gas sensing applications.

\begin{tabular}{|c|c|c|c|}
\hline \multicolumn{3}{|c|}{$\begin{array}{l}\text { 14. SUBJECT TERMS } \\
\mathrm{SiC} \text {; Gas; Emission; Sensor; High temperature }\end{array}$} & \multirow{2}{*}{\begin{tabular}{|c|}
$\begin{array}{c}\text { 15. NUMBER OF PAGES } \\
10\end{array}$ \\
A02 \\
16. PAICE CODE \\
20. LIMITATION OF ABSTRACT
\end{tabular}} \\
\hline $\begin{array}{l}\text { 17. SECURITY CLASSIFICATION } \\
\text { OF REPORT }\end{array}$ & $\begin{array}{l}\text { 18. SECURITY CLASSIFICATION } \\
\text { OF THIS PAGE }\end{array}$ & $\begin{array}{l}\text { 19. SECUAITY CLASSIFICATION } \\
\text { OF ABSTRACT }\end{array}$ & \\
\hline Unclassified & Unclassified & Unclassified & \\
\hline
\end{tabular}

